\title{
Structure of hepatitis C virus envelope glycoprotein E1 antigenic site 314-324 in complex with antibody IGH526
}

Leopold Kong ${ }^{1}$, Rameshwar U. Kadam ${ }^{1}$, Erick Giang ${ }^{2}$, Tinashe B. Ruwona ${ }^{2}$, Travis Nieusma ${ }^{1}$, Jeffrey C. Culhane ${ }^{3,4}$, Robyn L. Stanfield ${ }^{1}$, Philip E. Dawson ${ }^{3,4}$, Ian A. Wilson ${ }^{1,5}$, and Mansun Law $^{2 *}$

1 - Department of Integrative Structural and Computational Biology, The Scripps Research Institute, La Jolla, CA, USA.

2 - Department of Immunology and Microbial Science, The Scripps Research Institute, La Jolla, CA, USA.

3 - Department of Chemistry, The Scripps Research Institute, La Jolla, CA, USA.

4 - Department of Cell and Molecular Biology, The Scripps Research Institute, La Jolla, CA, USA.

5 - The Skaggs Institute for Chemical Biology, The Scripps Research Institute, La Jolla, CA, USA.

*Correspondence to Ian A. Wilson and Mansun Law: wilson@scripps.edu and mlaw@scripps.edu. 


\section{Highlights:}

- IGH526 is a cross-neutralizing antibody that recognizes HCV E1 glycoprotein

- IGH526 binds a discontinuous epitope with a linear component near the terminal membrane proximal region of $\mathrm{E} 1$

- The linear component of the epitope is $\alpha$-helical when bound to IGH526

- Molecular dynamics suggest the unliganded E1 linear peptide is flexible in solution

- This study defines the first target on HCV E1 for structure-based immunogen design

Key words: HCV; E1 envelope glycoprotein; IGH526; vaccine design 


\section{Introduction}

Hepatitis $\mathrm{C}$ virus (HCV) infects more than 150 million people worldwide and is a leading cause of liver cirrhosis and hepatocellular carcinoma in developed countries ${ }^{1,2}$. It is estimated that 3-4 million people are newly infected each year ${ }^{2,3}$. Recent advances in direct-acting anti-viral (DAA) drug development have given hope for curing this devastating human disease ${ }^{4-6}$. However, as many of the new infections are associated with injecting drug usage (IDU), particularly in young adults in developed countries and in regions along illegal drug trafficking routes ${ }^{7,8}$, it is unclear how the new treatments could be effectively disseminated to these marginalized and sometimes mobile populations. Furthermore, recent studies have shown that treated patients are not entirely immune to reinfection ${ }^{9,10}$, indicating DAA treatment alone will not be sufficient in controlling the HCV endemic. Considering the socio-economic factors associated with $\mathrm{HCV}$ infection, an effective vaccine will be needed to combat this human pathogen.

$\mathrm{HCV}$ is a single-stranded, positive-sense RNA virus in the Flaviviridae family. The 9.6-kb virus genome encodes a single open reading frame and the translated polypeptide is processed further by host and viral proteases into 10 viral proteins ${ }^{11}$. A T-cell based vaccine, based on adenovirus and poxvirus vectors expressing the non-structural proteins NS3, NS4A, NS4B, NS5A and NS5B, is currently being evaluated in a phase II clinical trial ${ }^{12}$. Another vaccine candidate, based on the structural envelope glycoproteins E1 and E2, has been evaluated in different animal models including chimpanzees ${ }^{13}$ and in a phase I study ${ }^{14}$. This candidate subunit vaccine was safe in humans and elicited moderate level of virus neutralizing antibodies in some of the test subjects ${ }^{15,16}$. However, the results suggest that, for a subunit vaccine to be efficacious, the antigenicity and immunogenicity of the vaccine antigens must be improved through rational vaccine design.

The E1 and E2 glycoproteins form a heterodimer (E1E2) on the viral surface and mediate viral entry ${ }^{11,17}$. E2 is the receptor binding protein, but the function of E1 is currently unknown. Developing an HCV vaccine is challenging due to the high antigenic variability of E1 and E2 ${ }^{18}$, ${ }^{19}$. Structural characterization of cross-reactive neutralizing antibody (NAb) epitopes on E1 or E2 can therefore provide templates for vaccine design to circumvent this variability.

E1 is known to be less immunogenic compared to E2 ${ }^{20}$. However, two E1 regions targeted by monoclonal antibodies (MAb) have been identified: residues 192-202, which are recognized by the weakly neutralizing MAb H-111 ${ }^{21}$; and residues 313-328, which interact with the crossreactive NAbs IGH526 and IGH505 ${ }^{22}$. MAb IGH526, the subject of this study, is of particular interest because it has been shown to cross-react with and cross-neutralize several HCV genotypes ${ }^{22}$. Its epitope has been mapped to E1 residues 313-328 using a library of overlapping 
peptides of E1 and site-directed mutagenesis. Residues 313-328 are nearly universally conserved ${ }^{23}$ and are recognized by 30 of $92 \mathrm{HCV}$ patient sera ${ }^{24}$, and 15 of 41 vaccinee sera ${ }^{16}$, thereby representing a promising antigenic target for vaccine design. Previously, NMR was used to characterize E1 residues 314-342 ${ }^{25}$, with results indicating that residues 319-323 adopt a helical conformation, while residues 314-315 and 324-328 do not have regular secondary structure. Although this NMR study suggested a helical propensity for residues 313-328, the NMR measurements were performed in the presence of 50-80\% hexafluoroisopropanol, which can induce helical conformation in peptides ${ }^{26,27}$. Also, for vaccine design, it is critical to determine the conformation of epitopes recognized by NAbs. Therefore, in the present study, we sought to characterize MAb IGH526, which could be of great utility for studying HCV E1, and for obtaining structural information on this major E1 antigenic site for rational vaccine design.

\section{Results}

MAb IGH526 is a neutralizing antibody recognizing a discontinuous epitope that includes a linear component on E1

MAb IGH526 was cloned and expressed in mammalian FreeStyle ${ }^{\mathrm{TM}} 293 \mathrm{~F}$ cells as full-length IgG1. First, we examined its biological activity. In virus neutralization assays, IGH526 neutralized the prototypic $\mathrm{HCV}$ strain $\mathrm{H} 77$ albeit less potently than the well-characterized antiE2 MAb AR3A or anti-E1E2 MAb AR4A (Fig. 1a) ${ }^{28}$. Second, we showed that two overlapping peptides spanning E1 region 313-327 specifically blocked its binding to E1E2 (Fig. 1b), confirming the epitope mapping results from a previous study ${ }^{22}$. However, when E1E2 was reduced and denatured, binding of MAb IGH526 in ELISA was nearly abolished (Fig. 1c). Furthermore, the antibody also did not recognize E1 in immunoblots (data not shown). Together, the observations suggest IGH526 recognizes a linear region at residues 313-327 on E1, but that there might be additional regions on E1 or E2 involved since binding is severely decreased on E1/E2 denaturation. In an attempt to find these regions, the antibody was tested against a panel of overlapping peptides spanning the viral structural proteins Core (residues 1-191), E1 and E2. The results showed that IGH526 bound only to the previously identified E1 peptide (Fig. 1d). For comparison with a positive control, we performed the same experiment for MAb HCV1, a broadly neutralizing antibody that is known to recognize a linear region in E2 ${ }^{29}$, which this assay clearly confirmed. This is in agreement with the observation above that binding of MAb IGH526 to E1E2 could be blocked entirely by peptides encoding the putative linear epitope (Fig. 1). Together, the results indicate that MAb IGH526 recognizes a discontinuous epitope on either E1 or E1E2, with a major component appears to be a linear epitope spanning E1 region 313-327.

\section{Crystal structure of Fab IGH526 bound to an E1 peptide reveals a helical epitope}


We used x-ray crystallography to characterize how MAb IGH526 interacts with the linear component of its epitope. MAb IGH536 Fab was generated and its crystal structure was determined at $1.75 \AA$ resolution in complex with an 11-residue peptide (amidated at the Cterminus), corresponding to E1 residues 314-324) (Table S1 and Fig. S1). The peptide (TGHRMAWDMMM) adopts a 2.5-turn $\alpha$-helix when bound to IGH526 Fab (Fig. 2a). The peptide is wedged against an extended 16-residue CDR H3 loop and inserted into a shallow cleft formed by the CDR H1, H2, L1, and L3 loops. Lack of CDR L2 contact is not uncommon for small molecule or peptide antigens ${ }^{30}$. Overall, IGH526 Fab buries $530 \AA^{2}$ of the peptide surface; the binding interface consists of 126 van der Waals interactions, four hydrogen bonds and one aromatic hydrogen bond (Tables S2 and S3). Four hydrogen bonds between the antibody and the peptide main chain form interactions with the peptide in a side-chain independent manner (Fig. 2b). The antibody-antigen union is further enhanced by specific interactions with His 316 and Trp320, two of the bulkier residues on the antigen, with the antibody (Fig. 2b and 2c): (i) an aromatic hydrogen bond ${ }^{31}$ is formed between the backbone amide of Phe ${ }^{\mathrm{H} 98}$ of CDR H3 and the electronegative phenyl ring of the Trp320 indole (Fig. 2b, bottom left); (ii) water-mediated hydrogen bonds are made to both imidazole nitrogens of His316 by Asp ${ }^{\mathrm{H} 95}$ of CDR H3 and $\mathrm{Thr}^{\mathrm{L} 32}$ of CDR L1 (Fig. 2c, top); and (iii) a water-mediated hydrogen bond is made between the backbone carbonyl of Asp ${ }^{\mathrm{H} 95}$ in $\mathrm{CDR} \mathrm{H} 3$ and the indole $\mathrm{N}-\mathrm{H}$ of Trp320 (Fig. 2c, bottom). The structure suggests that this E1 helix cannot be extended further in the intact protein as any extension of the helix on the N-terminal or C-terminal side would quickly result in severe clashes with the antibody (Fig. S2).

\section{Mutagenesis of IGH526 epitope residues severely inhibits IGH526 binding to membrane- extracted E1E2 but does not disrupt IGH526 neutralizing activity}

Previous epitope mapping using peptides showed that substitution of His316, Ala319, Trp320 Met323, and Met324 to alanine or glycine had the most impact on IGH526 binding ${ }^{22}$ in general agreement with the structure (Fig. 2d-e), which shows these residues contact multiple antibody residues and are substantially buried within the antibody-antigen interface. Arg317 at the perimeter of the interface has a substantial interaction with the antibody, but mutation to alanine only modestly reduced binding. To further investigate this epitope, we introduced single mutations into E1E2 for binding and neutralization studies. The binding assays with membraneextracted E1E2 show that alanine/glycine replacement at His316, Trp320 and Met323 had the most impact, followed by Ala319, Met324 and also Arg317 (Fig. 3a). These residues all face the antibody in the peptide-complex structure, while mutations on the non-binding side of the helix (Met318, Asp321 and Met322) had less impact on antibody binding. In a functional study, alanine mutation at Gly315, Met318, Asp321, Met322 or Met323 completely abolished viral infectivity (Fig. 3b), suggesting these residues may be important in protein folding by interacting with other portions of E1E2. Surprisingly, despite severe loss of binding to the antibody in ELISA, the H316A and W320A single mutants were less sensitive to IGH526 neutralization, 
(Fig. 3b-d), indicating that the single mutations did not disrupt the epitope on the virus to the same extent as observed in membrane-extracted E1E2 or in linear peptides ${ }^{22}$. However, a H316A/W320A double mutant could not be neutralized by IGH526 even at high antibody concentrations (Fig. 3c-d).

\section{Molecular dynamics suggests the linear component of the IGH526 epitope is highly flexible}

While structural characterization of the E1 ectodomain or the E1E2 complex will be required to fully define the IGH526 epitope, the crystal structure of the peptide complex revealed the high affinity linear component of the epitope, which could serve as a starting point for vaccine design. Therefore, we sought to further characterize the stability and conformational dynamics of this E1 peptide. Molecular dynamics (MD) simulations were conducted for $25 \mathrm{~ns}$ on the bound and unbound peptides starting from the crystal structure coordinates (Fig. 4 and Fig. S3). When bound, the peptide maintained a similar conformation as in the crystal structure with a $\mathrm{C} \alpha$ root mean square deviation (RMSD) of $0.42 \pm 0.1 \AA$, calculated over the last 15 ns (Fig. 4a and 4c). When unbound, the peptide unfolded at the N-terminus during 3-8 ns, but remained helical at Ala319-Met324 throughout most of the simulation (Fig. 4b and 4c). Accordingly, the Ca RMSD, calculated over the last $15 \mathrm{~ns}$, across the whole peptide, relative to the crystal structure, was $3.4 \pm 0.1 \AA$, while the C $\alpha$ RMSD of just Ala319-Met324 was $0.38 \pm 0.1 \AA$ (Fig. 4b and Fig. S3). This simulation is consistent with Ala319-Met325 containing three methionines and one alanine, residues that have high helical propensity ${ }^{32}$. In the synthetic peptide, the C-terminal region is further stabilized by the amidated C-terminus, which forms a hydrogen bond with the backbone carbonyl of Asp321.

\section{Discussion}

In this study, we sought to characterize the epitope of the anti-E1 MAb IGH526. Although this antibody is not as potent as some anti-E2 MAbs isolated, it cross-reacts with multiple HCV isolates by recognizing an immunogenic and highly conserved region on E1 ${ }^{16,22}$. Furthermore, it is one of the few anti-E1 MAbs available and, therefore, an invaluable reagent for study of this recalcitrant protein, whose function for the virus remains unknown. E1 is challenging to study because it requires co-expression with E2 and forms heterogeneous soluble aggregates of E1E2 even when expressed without the transmembrane domain ${ }^{33-36}$. The absence of a folded E1 independent of E2 renders it difficult to determine whether IGH526, isolated from infected patients, interacts with E1 only or with the E1E2 complex. The recently published structure of the E1 N-terminus domain reveals a unique cross-linked organization, suggesting E1E2 could be

presented as a multimeric oligomer on the virus ${ }^{37}$. While it is unclear how closely the membrane extracted E1E2 used for binding studies here resemble the functional oligomer on the virus, as shown above, IGH526 appeared to distinguish between them since it retained neutralizing ability against viruses harboring mutations that abrogated binding to extracted E1E2. These results and 
the observation that the antibody failed to bind denatured E1E2 highlight the complexity of the IGH526 epitope; a complete definition would require structural characterization of the functional E1E2 oligomer. Because this is hindered by technical challenges in producing well-behaved, soluble protein, we focused on the linear component of the IGH526 epitope initially identified by peptide scanning.

The crystal structure of the antibody-bound peptide complex revealed a helical conformation of the linear component interacting with IGH526 across one face. This finding corroborates with the previously published NMR study of a longer peptide indicating helical propensity for the same region ${ }^{25}$. Of note, E1 region is primarily hydrophobic, suggesting it may be proximal to the viral membrane ${ }^{38}$. Furthermore, the residues in this region are nearly universally conserved across all HCV strains despite high sequence variability, consistent with membrane proximal regions of other viruses like HIV ${ }^{22,}{ }^{39}$. In this regard, IGH526 may resemble anti-HIV MAb 4E10, which binds to a highly conserved membrane proximal helix of gp41 ${ }^{40}$. MAb 4E10 displays reactivity towards lipid, which raises the same possibility for IGH526, and could be an explanation for why IGH526 recognizes membrane-bound E1E2 differently. Again, further study of the antibody in a more functional context is required to test this possibility.

Finally, by elucidating the binding surface of IGH526 on the $\alpha$-helical peptide, we have provided a first template of E1 for immunogen design. Furthermore, MD simulations suggested the free peptide is flexible, particularly at its N-terminus, which matches the previous NMR study ${ }^{25}$. Therefore, it will be critical to stabilize the free peptide as a short helix and enhance the presentation of the binding surface through multimerization of this E1 antigenic site on a nanoparticle. Although this linear region does not appear to represent the complete epitope of IGH526, stabilized immunogens may be useful in boosting the immune response towards this highly conserved antigenic site after an initial prime by soluble E1E2.

\section{Materials and Methods}

\section{Antibody production}

The $\mathrm{V}_{\mathrm{H}}$ and $\mathrm{V}_{\mathrm{L}}$ domains of human antibody IGH526 ${ }^{22}$ were synthesized (GenScript) and fused with human $\mathrm{C}_{\mathrm{H}} 1-3$ and $\mathrm{C}_{\mathrm{K}}$ domains using the $\mathrm{pIgG} 1$ vector ${ }^{41}$ for high-level protein expression of a complete $\mathrm{IgG}$ by transient transfection of $293 \mathrm{~F}$ cells. To prepare the Fab fragment for crystallization studies, $\mathrm{C}_{\mathrm{H}}$ 2-3 domains in the expression vector were deleted and soluble Fab was produced by transient transfection of $293 \mathrm{~F}$ cells with the recombinant DNA. The Fab was purified by affinity chromatography using a rabbit anti-human Fab antibody column followed by size exclusion chromatography with a Superdex 200 column (GE Healthcare). 


\section{Synthesis of the TGHRMAWDMMM.amide peptide}

Rink Amide AM resin (282 mg, $0.2 \mathrm{mmol}$ ) (Novabiochem, 200-400 mesh, $0.71 \mathrm{mmol} / \mathrm{g}$ substitution) was weighed directly into a disposable solid-phase peptide synthesis (SPPS) reaction vessel (CSPS Pharmaceuticals) and swelled with $N, N$-Dimethylformamide (DMF) for one hour. Fmoc protecting group removal was accomplished by two treatments of the resin with 20\% 4-methylpiperidine in DMF for a duration of two minutes each. After thorough washing of the resin with DMF, the appropriate Fmoc amino acid $(1.0 \mathrm{mmol})$ was dissolved in a solution of 1H-Benzotriazolium 1-[bis(dimethyl-amino)methylene]-5-chloro-hexafluorophosphate (1-),3oxide (HCTU) in DMF (2.5 mL, $0.4 \mathrm{M})$ in a scintillation vial. Diisopropylethylamine $(261 \mu \mathrm{L}$, $1.5 \mathrm{mmol}$ ) was added to the vial. After 30s of preactivation, the contents of the vial were added to the drained but wetted resin. Coupling was performed for 45 minutes. At the end of the synthesis, the resin was washed with dichloromethane (DCM) and dried under vacuum for 1 hour. Cleavage from the solid-phase was achieved using 95\% trifluoroacetic acid/2.5\% $\mathrm{H}_{2} \mathrm{O} / 2.5 \%$ triisopropylsilane for $2 \mathrm{~h}$. The resin was filtered and the TFA was concentrated with a stream of nitrogen prior to the peptide being precipitated by the addition of cold diethyl ether. Peptide was pelleted by centrifugation and dissolved in $30 \%$ acetonitrile in water containing $0.05 \%$ TFA prior to being flash frozen and lyophilized. Crude peptide was purified by RPHPLC. Electrospray mass spectrometry confirmed the identity of the peptide as the expected product (expected: $1365.6 \mathrm{amu}$, found: $1365.4 \mathrm{amu}$ ).

\section{Enzyme-linked immunosorbent assay (ELISA)}

(i) To determine whether the antibodies recognized native, reduced or mutant E1E2, the antigens were captured onto ELISA wells (Maxisorp ELISA plates, Corning) that were pre-coated with Galanthus nivalis lectin ( $5 \mu \mathrm{g} / \mathrm{ml}$, Sigma) (folded protein), or unfolded with $0.1 \%$ SDS, $50 \mathrm{mM}$ DTT and incubated at $56^{\circ} \mathrm{C}$ for 15 min before capture onto ELISA wells (unfolded protein). E1E2 and mutant antigens were prepared from cell lysates of 293T cells transfected with $\mathrm{H} 77$ E1E2-expression plasmid ${ }^{42}$. Non-fat milk (4\%, BioRad) in PBS and $0.05 \%$ Tween 20 was used as a blocker in assays using lectin-captured antigens. The ELISA plates were washed after $1 \mathrm{~h}$ incubation and binding of antibodies was detected by peroxidase (HRP)-conjugated goat antihuman IgG Fc or anti-mouse IgG secondary antibody (1:2000) (Pierce) and TMB substrate (Pierce). (ii) To study the ability of peptides in inhibiting MAb IGH526 binding to E1E2, the peptides and $\mathrm{mAb}$ were mixed at the specified ratio and incubated for $30 \mathrm{~min}$ before adding to ELISA microwells coated with lectin-captured E1E2. After $1 \mathrm{~h}$ incubation, the plates were washed and bound antibody was detected with secondary antibody and chromogenic substrate as above. (iii) To study the peptide specificity of antibodies, a series of overlapping peptides consisting of 18-mers, with an overlap of 12 amino acids covering the E1E2 HCV glycoprotein region was used. The peptides were obtained from NIH AIDS Research \& Reference Reagent Program, as HCV type 1a H77 (18-mer) Peptides - Complete Set (Cat\# 7620, LOT\# 4). The 

plates were coated with $200 \mathrm{ng} /$ well of peptide in duplicate, after blocking the plates were incubated with $10 \mu \mathrm{g} / \mathrm{ml}$ of antibody for an hour and binding signals were developed and measured as above.

\section{Virus neutralization assay}

Neutralization assays were performed in Dulbecco's Modified Eagle Medium (D-MEM) supplemented with 10\% fetal calf serum (FCS) (Invitrogen). HCVpp was generated by cotransfection of $293 \mathrm{~T}$ cells with $\mathrm{pNL} 4-3$ LucR $^{-} \mathrm{E}^{-43,44}$ and the corresponding expression plasmids encoding the E1E2 genes at $4: 1$ ratio by polyethylenimine ${ }^{45}$. Virus infectivity was detected using the firefly luciferase assay system (Promega) and \% neutralization was calculated as residual virus infectivity at the indicated antibody concentrations divided by infectivity without antibody after background subtraction. Background infectivity of the pseudotype virus was determined using cells transfected with pNL4-3.lucR ${ }^{-} E^{-}$only and VSVpp was a control for nonspecific activity. In the neutralization assay, the virus was incubated with the diluted antibodies for $1 \mathrm{~h}$ at $37^{\circ} \mathrm{C}$ before adding to Huh-7 cell monolayers and incubated for another $6 \mathrm{~h}$. For virus with low infectivity, the $6 \mathrm{~h}$ incubation step was replace with spinoculation at $800 \mathrm{~g}$ for $1 \mathrm{~h}$. Expression of the luciferase reporter gene in the infected cells was measured 3 days post infection.

\section{Complex formation and crystallization}

The IGH526 Fab was concentrated to $8-12 \mathrm{mg} / \mathrm{mL}$ using an Amicon centrifugal ultrafiltration unit (Millipore) with a $10 \mathrm{kDa}$ molecular weight cutoff. The concentrated Fab and E1 peptide were incubated at a 1:10 molar ratio overnight at $4^{\circ} \mathrm{C}$ in $150 \mathrm{mM} \mathrm{NaCl}, 20 \mathrm{mM}$ Tris- $\mathrm{HCl} \mathrm{pH} 7.2$ to form the complex. Samples were screened for crystallization using the 384 conditions of the JCSG Core Suite (Qiagen) at both 277 and 293 K using the JCSG robotic Crystalmation system (Rigaku). Crystallization was performed using the nanodroplet vapor diffusion method ${ }^{46}$ with standard JCSG crystallization protocols ${ }^{47}$. Sitting drops composed of $200 \mathrm{nl}$ of protein sample were mixed with $200 \mathrm{nl}$ of crystallization reagent in a sitting drop format and were equilibrated against a $50 \mu \mathrm{l}$ reservoir of crystallization reagent. After approximately 7 days at $20^{\circ} \mathrm{C}$, crystals formed in 20\% (w/v) PEG 6000, 1M lithium chloride and 0.1 M citric acid, pH 4.0 (JCSG Core Suite 1, well H10).

\section{X-ray data collection}

IGH526-peptide complex crystals diffracted to $1.75 \AA$ at beamline 23ID-D of the Advanced Photon Source (APS). Data were collected at $100 \mathrm{~K}$ to a completeness of $100 \%$ with an overall $R_{\text {sym }}$ of $9 \%$ and $R_{\text {pim }}$ of $4 \%$ (Table 1 ). Data were indexed, processed and scaled with HKL-2000 
${ }^{48}$ in orthorhombic space group $\mathrm{P} 2{ }_{1} 2_{1} 2_{1}$ with unit cell parameters $a=66.3 \AA, b=67.6 \AA, c=$ $120.7 \AA$. One protein-peptide complex is present per asymmetric unit with a Matthews' coefficient $(\mathrm{Vm})$ of $2.71 \AA^{3} / \mathrm{Da}$ and solvent content of $54.6 \%$.

\section{Structure determination and refinement}

The structure was determined by molecular replacement using Phaser ${ }^{49}$ with the HCV1 Fab structure (PDB ID: 4DGV) as an initial model. Model building was carried out using Coot-0.6.2 ${ }^{50}$ and refinement was implemented with Phenix ${ }^{51}$. Final $\mathrm{R}_{\text {cryst }}$ and $\mathrm{R}_{\text {free }}$ values are $18.4 \%$ and $21.5 \%$, respectively. Buried molecular surface areas were analyzed with $\mathrm{MS}^{52}$ using a $1.7 \AA$ probe radius and standard van der Waals radii, and van der Waals contacts and hydrogen bonds were evaluated with CONTACSYM ${ }^{53,54}$ and HBPLUS ${ }^{55}$. Surface potential and electrostatics were calculated using APBS ${ }^{56}$ and all structural visualizations were generated with PyMOL (The PyMOL Molecular Graphics System, Version 1.2r3pre, Schrödinger, LLC.). For the Fab, the residues were numbered according to the Kabat scheme ${ }^{57}$.

\section{Molecular dynamics (MD) simulations}

(i) Peptide and peptide-antibody structure preparation for MD. The starting structural coordinates for unbound peptide and peptide-antibody were obtained from the IGH526 complex structure solved in this study. The structures were prepared by assigning bond orders and adding hydrogen atoms using default protocol from the protein preparation wizard interface with Maestro 8.5 in Schrödinger biologics suite (www.schrodinger.com). Force field parameters for standard amino acid residues were obtained from OPLS-AA (Optimized Potentials for Liquid Simulations-All Atom) force field ${ }^{58}$.

(ii) MacroModel energy optimizations. Optimized structures were subsequently minimized in MacroModel 9.7 in Schrödinger biologics suite using steepest descent method with maximum of 500 iterations with gradient convergence threshold of 0.05 and constant dielectric with dielectric constant of 1. The OPLS-AA force field with extended cutoff values (van der Waals = 8.0 electrostatic $=20.0 \AA$; H-bond $=4.0 \AA$ ) was used for the minimizations.

(iii) System preparation for simulations. MD simulations were performed using OPLS-AA force field in Desmond MD package with Maestro-Desmond interoperability tool, version $2.0^{59}$. The systems were set up for explicit solvent simulations. The solute was placed in an orthorhombic box containing SPC water ${ }^{60}$ at $1.5 \mathrm{~nm}$ from solute boundaries. The physiological salt concentration of $0.15 \mathrm{M}$ was used.

(iv) MD simulations. MD simulations for a period of $25 \mathrm{~ns}$ were performed for both structures using the following three steps protocol: minimization; equilibration; and production run. Minimization. The setup systems were minimized to remove close contacts between solutesolvent molecules using the Limited Memory Broyden-Fletcher-Goldfarb-Shanno (LBFGS) method with maximum iterations of 200 cycles and convergence threshold of $1.0 \mathrm{Kcal} \mathrm{mol}^{-1} \AA^{-1}$. 
The step size was $0.005 \mathrm{ps}$ and the switch criterion was $25.0 \mathrm{Kcal}^{\mathrm{mol}}{ }^{-1} \AA^{-1}$. The short-range interactions used cutoff radius of $9.0 \AA$, whereas the long-range Coulombic interactions were taken into account using smooth Particle Mesh Ewald (PME) with Ewald tolerance of $1 \mathrm{e}^{-09} \AA$.

Equilibration protocol. During equilibration, 2000 steps of steepest descent minimization of water molecules and ions were performed to allow water molecules to assume a lower energy geometry, while the solute was restrained with a force constant of $50 \mathrm{kcal} / \mathrm{mol} \AA^{2}$. The resulting systems were then subjected to 2000 steps of minimization with no restraints, reaching a root mean square gradient of 0.1 to assure the relaxation of the structures, followed by $12 \mathrm{ps}$ of heating from 10 to $300 \mathrm{~K}$ in a constant volume ensemble with restraints on the solute heavy atoms $\left(50 \mathrm{kcal} / \mathrm{mol} \AA^{2}\right)$. Annealing was followed by $12 \mathrm{ps}$ of constant pressure unrestrained simulation at $300 \mathrm{~K}$, where convergences of energies, temperature, pressure and density of the systems was monitored.

Production runs protocol. The output coordinates and velocities from the equilibrated run were subsequently used in production runs over a period of $25 \mathrm{~ns}$ at $300 \mathrm{~K}$ using an isothermalisobaric (NPT) ensemble. Hydrogen bonds were constrained with a variant of the M-SHAKE algorithm ${ }^{61}$. To maintain $1 \mathrm{~atm}$ at $300 \mathrm{~K}$ in NPT ensemble, the system was coupled to a Martyna-Tobias-Klein barostat ${ }^{62}$ with relaxation time of 2 ps with isotropic coupling style, and a Nose-Hoover thermostat with relaxation time of $1 \mathrm{ps}^{63}$. Long-range electrostatic interactions were modeled using a Particle Mesh Ewald method ${ }^{64}$ and a $64 \times 64 \times 64$ Fourier space mesh with fifth-order B spline interpolation. The van der Waals (VDW) interactions and real space contributions to the electrostatics were truncated at $10 \AA$, and estimated the long-range VDW contributions to the energy and the pressure by assuming a homogeneous distribution of VDW spheres with dispersion coefficient $69.5 \mathrm{kcal} / \mathrm{mol} / \mathrm{A}$. RESPA integrator ${ }^{65}$ with steps of 2 fs was used for bonded and short-range non bonded interactions, and 6 fs for long-range electrostatics. During the course of simulations, quality checks of the system were performed by monitoring the total energy profile and the $\mathrm{C} \alpha \mathrm{RMSD}$ of structures in MD trajectories.

\section{Accession numbers:}

The atomic coordinates have been deposited in the Protein Data Bank, www.pdb.org (PBD ID code $4 \mathrm{~N} 0 \mathrm{Y})$.

\section{Acknowledgements}

We thank Henry Tien and Thomas Clayton for help in setting up initial crystal screens using the JCSG Crystalmation robot. We would also like to thank Jane Verenini for help in formatting the manuscript. Portions of this research were carried out at the Advanced Photon Source (APS) beamline 23ID-D. Use of the APS was supported by the US Department of Energy, Basic Energy Sciences, Office of Science, under contract no. DE-AC02-06CH11357. This work is supported by NIH grants AI079031 and AI106005 (to M.L.), AI084817 (to I.A.W.), U54 
GM094586 (to I.A.W.), and the Skaggs Institute (I.A.W.). R.U.K is grateful to the Swiss National Science Foundation for a post-doctoral fellowship. This is TSRI manuscript number 21874.

\section{Competing interests statement}

The authors declare no conflict of interest.

\section{REFERENCES}

1. Lavanchy, D. (2011). Evolving epidemiology of hepatitis C virus. Clin. Microbiol. Infect. $17,107-115$.

2. Mohd Hanafiah, K., Groeger, J., Flaxman, A. D. \& Wiersma, S. T. (2013). Global epidemiology of hepatitis $\mathrm{C}$ virus infection: new estimates of age-specific antibody to HCV seroprevalence. Hepatology 57, 1333-1342.

3. Kane, A., Lloyd, J., Zaffran, M., Simonsen, L. \& Kane, M. (1999). Transmission of hepatitis B, hepatitis $\mathrm{C}$ and human immunodeficiency viruses through unsafe injections in the developing world: model-based regional estimates. Bull. World Health Organ. 77, 801-807.

4. Feeney, E. R. \& Chung, R. T. (2014). Antiviral treatment of hepatitis C. BMJ 348, g3308.

5. Gane, E. J. \& Agarwal, K. (2014). Directly acting antivirals (DAAs) for the treatment of chronic hepatitis $\mathrm{C}$ virus infection in liver transplant patients: "a flood of opportunity". Am. J. Transplant. 14, 994-1002.

6. Pawlotsky, J. M. (2014). New hepatitis C therapies: the toolbox, strategies, and challenges. Gastroenterology 146, 1176-1192.

7. Onofrey, S., Church, D., Kludt, P., DeMaria, A., Cranston, K., Beckett, G. A., Holmberg, S. D., Ward, J. W. \& Holtzman, D. (2011). Hepatitis C virus infection among adolescents and young adults:Massachusetts, 2002-2009. MMWR Morb. Mortal. Wkly. Rep. 60, 537541.

8. Zhang, Z., Yao, Y., Wu, W., Feng, R., Wu, Z., Cun, W. \& Dong, S. (2013). Hepatitis C Virus genotype diversity among intravenous drug users in Yunnan Province, Southwestern China. PLoS ONE 8, e82598. 
9. Grady, B. P., Schinkel, J., Thomas, X. V. \& Dalgard, O. (2013). Hepatitis C virus reinfection following treatment among people who use drugs. Clin. Infect. Dis. 57 Suppl 2, S105-110.

10. Marco, A., Esteban, J. I., Sole, C., da Silva, A., Ortiz, J., Roget, M., Sarriera, C., Teixido, N., Guerrero, R. A. \& Cayla, J. A. (2013). Hepatitis C virus reinfection among prisoners with sustained virological response after treatment for chronic hepatitis C. J. Hepatol. 59, 45-51.

11. Lindenbach, B. D. \& Rice, C. M. (2013). The ins and outs of hepatitis C virus entry and assembly. Nat. Rev. Microbiol. 11, 688-700.

12. Swadling, L., Capone, S., Antrobus, R. D., Brown, A., Richardson, R., Newell, E. W., Halliday, J., Kelly, C., Bowen, D., Fergusson, J., Kurioka, A., Ammendola, V., Del Sorbo, M., Grazioli, F., Esposito, M. L., Siani, L., Traboni, C., Hill, A., Colloca, S., Davis, M., Nicosia, A., Cortese, R., Folgori, A., Klenerman, P. \& Barnes, E. (2014). A human vaccine strategy based on chimpanzee adenoviral and MVA vectors that primes, boosts, and sustains functional $\mathrm{HCV}$-specific $\mathrm{T}$ cell memory. Sci. Transl. Med. 6, 261 ra153.

13. Houghton, M. \& Abrignani, S. (2005). Prospects for a vaccine against the hepatitis C virus. Nature 436, 961-966.

14. Frey, S. E., Houghton, M., Coates, S., Abrignani, S., Chien, D., Rosa, D., Pileri, P., Ray, R., Di Bisceglie, A. M., Rinella, P., Hill, H., Wolff, M. C., Schultze, V., Han, J. H., Scharschmidt, B. \& Belshe, R. B. (2010). Safety and immunogenicity of HCV E1E2 vaccine adjuvanted with MF59 administered to healthy adults. Vaccine 28, 6367-6373.

15. Law, J. L., Chen, C., Wong, J., Hockman, D., Santer, D. M., Frey, S. E., Belshe, R. B., Wakita, T., Bukh, J., Jones, C. T., Rice, C. M., Abrignani, S., Tyrrell, D. L. \& Houghton, M. (2013). A hepatitis C virus (HCV) vaccine comprising envelope glycoproteins gpE1/gpE2 derived from a single isolate elicits broad cross-genotype neutralizing antibodies in humans. PLoS ONE 8, e59776.

16. Ray, R., Meyer, K., Banerjee, A., Basu, A., Coates, S., Abrignani, S., Houghton, M., Frey, S. E. \& Belshe, R. B. (2010). Characterization of antibodies induced by vaccination with hepatitis $\mathrm{C}$ virus envelope glycoproteins. J. Infect. Dis. 202, 862-866.

17. Kong, L., Jackson, K. N., Wilson, I. A. \& Law, M. (2015). Capitalizing on knowledge of hepatitis $\mathrm{C}$ virus neutralizing epitopes for rational vaccine design. Curr. Opin. Virol. 11, 148-157.

18. Kuiken, C. \& Simmonds, P. (2009). Nomenclature and numbering of the hepatitis C virus. Methods Mol. Biol. 510, 33-53. 
19. Kim, Y., Vaughan, K., Greenbaum, J., Peters, B., Law, M. \& Sette, A. (2012). A metaanalysis of the existing knowledge of immunoreactivity against hepatitis $\mathrm{C}$ virus (HCV). PLoS ONE 7, e38028.

20. Kohara, M., Tsukiyama-Kohara, K., Maki, N., Asano, K., Yamaguchi, K., Miki, K., Tanaka, S., Hattori, N., Matsuura, Y., Saito, I. \& et al. (1992). Expression and characterization of glycoprotein gp35 of hepatitis $\mathrm{C}$ virus using recombinant vaccinia virus. J. Gen. Virol. 73, 2313-2318.

21. Keck, Z. Y., Sung, V. M., Perkins, S., Rowe, J., Paul, S., Liang, T. J., Lai, M. M. \& Foung, S. K. (2004). Human monoclonal antibody to hepatitis C virus E1 glycoprotein that blocks virus attachment and viral infectivity. J. Virol. 78, 7257-7263.

22. Meunier, J. C., Russell, R. S., Goossens, V., Priem, S., Walter, H., Depla, E., Union, A., Faulk, K. N., Bukh, J., Emerson, S. U. \& Purcell, R. H. (2008). Isolation and characterization of broadly neutralizing human monoclonal antibodies to the E1 glycoprotein of hepatitis C virus. J. Virol. 82, 966-973.

23. Bukh, J., Purcell, R. H. \& Miller, R. H. (1993). At least 12 genotypes of hepatitis C virus predicted by sequence analysis of the putative $\mathrm{E} 1$ gene of isolates collected worldwide. Proc. Natl. Acad. Sci. USA 90, 8234-8238.

24. Siemoneit, K., Cardoso Mda, S., Koerner, K., Wolpl, A. \& Kubanek, B. (1995). Human monoclonal antibodies for the immunological characterization of a highly conserved protein domain of the hepatitis C virus glycoprotein E1. Clin. Exp. Immunol. 101, 278283.

25. Spadaccini, R., Errico, G., Alessio, V., Notomista, E., Bianchi, A., Merola, M. \& Picone, D. (2010). Structural characterization of the transmembrane proximal region of the hepatitis C virus E1 glycoprotein. Biochim. Biophys. Acta 1798, 344-353.

26. Hamada, D., Kuroda, Y., Tanaka, T. \& Goto, Y. (1995). High helical propensity of the peptide fragments derived from beta-lactoglobulin, a predominantly $\beta$-sheet protein. J. Mol. Biol. 254, 737-746.

27. Kumaran, S. \& Roy, R. P. (1999). Helix-enhancing propensity of fluoro and alkyl alcohols: influence of $\mathrm{pH}$, temperature and cosolvent concentration on the helical conformation of peptides. J. Pept. Res. 53, 284-293.

28. Giang, E., Dorner, M., Prentoe, J. C., Dreux, M., Evans, M. J., Bukh, J., Rice, C. M., Ploss, A., Burton, D. R. \& Law, M. (2012). Human broadly neutralizing antibodies to the envelope glycoprotein complex of hepatitis C virus. Proc. Natl. Acad. Sci. USA 109, 6205-6210. 
29. Kong, L., Giang, E., Robbins, J. B., Stanfield, R. L., Burton, D. R., Wilson, I. A. \& Law, M. (2012). Structural basis of hepatitis $C$ virus neutralization by broadly neutralizing antibody HCV1. Proc. Natl. Acad. Sci. USA 109, 9499-9504.

30. Wilson, I. A. \& Stanfield, R. L. (1994). Antibody-antigen interactions: new structures and new conformational changes. Curr. Opin. Struct. Biol. 4, 857-867.

31. Levitt, M. \& Perutz, M. F. (1988). Aromatic rings act as hydrogen bond acceptors. J. Mol. Biol. 201, 751-754.

32. Pace, C. N. \& Scholtz, J. M. (1998). A helix propensity scale based on experimental studies of peptides and proteins. Biophys. J. 75, 422-427.

33. Michalak, J. P., Wychowski, C., Choukhi, A., Meunier, J. C., Ung, S., Rice, C. M. \& Dubuisson, J. (1997). Characterization of truncated forms of hepatitis C virus glycoproteins. J. Gen. Virol. 78, 2299-2306.

34. Patel, J., Patel, A. H. \& McLauchlan, J. (2001). The transmembrane domain of the hepatitis C virus E2 glycoprotein is required for correct folding of the E1 glycoprotein and native complex formation. Virology 279, 58-68.

35. Brazzoli, M., Helenius, A., Foung, S. K., Houghton, M., Abrignani, S. \& Merola, M. (2005). Folding and dimerization of hepatitis C virus E1 and E2 glycoproteins in stably transfected CHO cells. Virology 332, 438-753.

36. Ruwona, T. B., Giang, E., Nieusma, T. \& Law, M. (2014). Fine mapping of murine antibody responses to immunization with a novel soluble form of hepatitis $\mathrm{C}$ virus envelope glycoprotein complex. J. Virol. 88, 10459-10471.

37. El Omari, K., Iourin, O., Kadlec, J., Sutton, G., Harlos, K., Grimes, J. M. \& Stuart, D. I. (2014). Unexpected structure for the $\mathrm{N}$-terminal domain of hepatitis $\mathrm{C}$ virus envelope glycoprotein E1. Nat. Commun. 5, 4874.

38. Hunte, C. (2005). Specific protein-lipid interactions in membrane proteins. Biochem. Soc. Trans. 33, 938-942.

39. Salzwedel, K., West, J. T. \& Hunter, E. (1999). A conserved tryptophan-rich motif in the membrane-proximal region of the human immunodeficiency virus type 1 gp41 ectodomain is important for Env-mediated fusion and virus infectivity. J. Virol. 73, 24692480.

40. Cardoso, R. M., Zwick, M. B., Stanfield, R. L., Kunert, R., Binley, J. M., Katinger, H., Burton, D. R. \& Wilson, I. A. (2005). Broadly neutralizing anti-HIV antibody 4E10 
recognizes a helical conformation of a highly conserved fusion-associated motif in gp41. Immunity 22, 163-173.

41. Law, M., Maruyama, T., Lewis, J., Giang, E., Tarr, A. W., Stamataki, Z., Gastaminza, P., Chisari, F. V., Jones, I. M., Fox, R. I., Ball, J. K., McKeating, J. A., Kneteman, N. M. \& Burton, D. R. (2008). Broadly neutralizing antibodies protect against hepatitis C virus quasispecies challenge. Nat. Med. 14, 25-27.

42. McKeating, J. A., Zhang, L. Q., Logvinoff, C., Flint, M., Zhang, J., Yu, J., Butera, D., Ho, D. D., Dustin, L. B., Rice, C. M. \& Balfe, P. (2004). Diverse hepatitis C virus glycoproteins mediate viral infection in a CD81-dependent manner. J. Virol. 78, 84968505.

43. Connor, R. I., Chen, B. K., Choe, S. \& Landau, N. R. (1995). Vpr is required for efficient replication of human immunodeficiency virus type-1 in mononuclear phagocytes. Virology 206, 935-944.

44. He, J., Choe, S., Walker, R., Di Marzio, P., Morgan, D. O. \& Landau, N. R. (1995). Human immunodeficiency virus type 1 viral protein $\mathrm{R}(\mathrm{Vpr})$ arrests cells in the $\mathrm{G} 2$ phase of the cell cycle by inhibiting p34cdc2 activity. J. Virol. 69, 6705-6711.

45. Boussif, O., Lezoualc'h, F., Zanta, M. A., Mergny, M. D., Scherman, D., Demeneix, B. \& Behr, J. P. (1995). A versatile vector for gene and oligonucleotide transfer into cells in culture and in vivo: polyethylenimine. Proc. Natl. Acad. Sci. USA 92, 7297-7301.

46. Santarsiero, B. D., Yegian, D. T., Lee, C. C., Spraggon, G., Gu, J., Scheibe, D., Uber, D. C., Cornell, E. W., Nordmeyer, R. A., Kolbe, W. F., Jin, J., Jones, A. L., Jaklevic, J. M., Schultz, P. G. \& Stevens, R. C. (2002). An approach to rapid protein crystallization using nanodroplets. J. Appl. Crystallogr. 35, 278-281.

47. Elsliger, M. A., Deacon, A. M., Godzik, A., Lesley, S. A., Wooley, J., Wuthrich, K. \& Wilson, I. A. (2010). The JCSG high-throughput structural biology pipeline. Acta Crystallogr. F Struct. Biol. Cryst. Commun. 66, 1137-1142.

48. Otwinowski, Z. \& Minor, W. (1997). Processing of X-ray diffraction data collected in oscillation mode. Methods Enzymol. 276A, 307-326.

49. McCoy, A. J., Grosse-Kunstleve, R. W., Adams, P. D., Winn, M. D., Storoni, L. C. \& Read, R. J. (2007). Phaser crystallographic software. J. Appl. Crystallogr. 40, 658-674.

50. Emsley, P., Lohkamp, B., Scott, W. G. \& Cowtan, K. (2010). Features and development of Coot. Acta Crystallogr. D Biol. Crystallogr. 66, 486-501. 
51. Adams, P. D., Afonine, P. V., Bunkoczi, G., Chen, V. B., Davis, I. W., Echols, N., Headd, J. J., Hung, L. W., Kapral, G. J., Grosse-Kunstleve, R. W., McCoy, A. J., Moriarty, N. W., Oeffner, R., Read, R. J., Richardson, D. C., Richardson, J. S., Terwilliger, T. C. \& Zwart, P. H. (2010). PHENIX: a comprehensive Python-based system for macromolecular structure solution. Acta Crystallogr. D Biol. Crystallogr. 66, 213-221.

52. Connolly, M. L. (1993). The molecular surface package. J. Mol. Graph. 11, 139-141.

53. Sheriff, S., Hendrickson, W. A. \& Smith, J. L. (1987). Structure of myohemerythrin in the azidomet state at 1.7/1.3 A resolution. J. Mol. Biol. 197, 273-296.

54. Sheriff, S., Silverton, E. W., Padlan, E. A., Cohen, G. H., Smith-Gill, S. J., Finzel, B. C. \& Davies, D. R. (1987). Three-dimensional structure of an antibody-antigen complex. Proc. Natl. Acad. Sci. USA 84, 8075-8079.

55. McDonald, I. K. \& Thornton, J. M. (1994). Satisfying hydrogen bonding potential in proteins. J. Mol. Biol. 238, 777-793.

56. Baker, N. A., Sept, D., Joseph, S., Holst, M. J. \& McCammon, J. A. (2001). Electrostatics of nanosystems: application to microtubules and the ribosome. Proc. Natl. Acad. Sci. U.S.A. 98, 10037-10041.

57. Martin, A. C. (1996). Accessing the Kabat antibody sequence database by computer. Proteins 25, 130-133.

58. Jorgensen, W. L., Maxwell, D. S. \& TiradoRives, J. (1996). Development and testing of the OPLS all-atom force field on conformational energetics and properties of organic liquids. J. Am. Chem. Soc. 118, 11225-11236.

59. Bowers, K. J., Chow, E., Xu, H., Dror, R. O., Eastwood, M. P., Gregersen, B. A., Klepeis, J. L., Kolossvary, I., Moraes, M. A., Sacerdoti, F. D., Salmon, J. K., Shan, Y. \& Shaw, D. E. (2006). Scalable algorithms for molecular dynamics simulations on commodity clusters. Proceedings of the 2006 ACM/IEEE Conference on Supercomputing (SC06); Tampa, Florida.

60. Roberts, B. P., Scanlon, M. J., Krippner, G. Y. \& Chalmers, D. K. (2009). Molecular dynamics of poly(L-lysine) dendrimers with naphthalene disulfonate caps. Macromolecules 42, 2775-2783.

61. Krautler, V., Van Gunsteren, W. F. \& Hunenberger, P. H. (2001). A fast SHAKE: Algorithm to solve distance constraint equations for small molecules in molecular dynamics simulations. J. Comput. Chem. 22, 501-508. 
62. Martyna, G. J., Tobias, D. J. \& Klein, M. L. (1994). Constant-Pressure MolecularDynamics Algorithms. J. Chem. Phys. 101, 4177-4189.

63. Hoover, W. G. (1985). Canonical dynamics: Equilibrium phase-space distributions. Phys. Rev. A 31, 1695-1697.

64. Darden, T. A., York, D. M. \& Pedersen, L. G. (1993). Particle mesh Ewald: An $\mathrm{N} \oplus \log (\mathrm{N})$ method for Ewald sums in large systems. J. Chem. Phys. 98, 10089-10092.

65. Tuckerman, M., Berne, B. J. \& Martyna, G. J. (1992). Reversible multiple time scale molecular-dynamics. J. Chem. Phys. 97, 1990-2001.

66. Giang, E., Dorner, M., Prentoe, J. C., Dreux, M., Evans, M. J., Bukh, J., Rice, C. M., Ploss, A., Burton, D. R. \& Law, M. (2012). Human broadly neutralizing antibodies to the envelope glycoprotein complex of hepatitis C virus. Proc. Natl. Acad. Sci. 109, 62056210 .

67. Dubuisson, J., Hsu, H. H., Cheung, R. C., Greenberg, H. B., Russell, D. G. \& Rice, C. M. (1994). Formation and intracellular localization of hepatitis C virus envelope glycoprotein complexes expressed by recombinant vaccinia and Sindbis viruses. J. Virol. 68, 6147-6160. 
FIG. 1. Biological activities of recombinant MAb IGH526. (a) Neutralization of HCV by MAb IGH526. The MAb neutralized HCV pseudotype virus particles (HCVpp) displaying the genotype 1a E1E2, but not the control envelope glycoprotein $G$ from vesicular stomatitis virus (VSVpp). MAbs AR3A and AR4A are control neutralizing MAbs to E2 and E1E2 complex, respectively ${ }^{66}$. (b) Binding of MAb IGH526 to E1E2 in ELISA can be blocked effectively by peptide H312 (HITGHRMAWDMMMNWS) or NIH 6971 (YPGHITGHRMAWDMMMNW). (c) Binding of MAb IGH526 to E1E2 in ELISA. E1E2 antigens expressed in 293T cells in their native (closed symbols) or reduced (open symbols) form were captured onto microwells by lectin. The control MAbs A4 and AR3A recognize a continuous E1 epitope ${ }^{67}$ and a discontinuous E2 epitope ${ }^{41}$, respectively. (d) Pepscan analysis of MAb IGH526. The antibody only bound a specific E1 peptide in a library of overlapping peptides (18-mer, 11-residue overlap, $250 \mathrm{ng} /$ well) spanning the viral structural proteins: Core, E1 and E2. MAb HCV1 is a control that binds the E2 412-423 region.

FIG. 2. Crystal structure of MAb IGH526 in complex with its E1 peptide epitope. (a) The overall structure of the IGH526 complex is shown in ribbon representation. The peptide epitope (red) is bound between the heavy (dark grey) and light (light grey) chains of the Fab. The CDR loops (H1-H3, L1-L3) are shown in different colors. (b) Hydrogen bonds and an aromatic hydrogen bond (bottom left) between residues on the E1 peptide (red) and antibody (gray) are shown. (c) Water molecules (green spheres) mediate hydrogen bonds between the E1 peptide and antibody. (d) The E1 peptide is represented as a helical wheel with the antibody residues that make van der Waals interactions and hydrogen bonds shown below each E1 contacting residue. The electrostatic character of each epitope residue is color-coded. (e) Burial of residues on the E1 peptide by IGH526 (above) and burial of CDR loops of IGH526 by the E1 peptide are shown.

FIG. 3. Characterization of the IGH526 epitope. (a) Alanine scanning mapping of the IGH526 epitope on E1E2 by ELISA. Left: Expression of the mutants was confirmed by the anti-E2 MAb AR2A $(1 \mu \mathrm{g} / \mathrm{mL})^{41}$. Center and right: Binding of MAb IGH526 to the variants. Note enhanced binding was observed for the W326A mutant, while the majority of the mutants bound at similar (filled symbols) or reduced (grey symbols) levels compared to wildtype E1E2. Binding was abolished for the mutants H316A, W320A and M323A. (b) Effects of alanine substitution on viral infectivity and antibody neutralization. HCV pseudotype virus particles (HCVpp) bearing the specific alanine/glycine substitutions were generated as described previously ${ }^{41}$. The infectivity of the mutant panel was evaluated based on the activity of the HCVpp reporter gene luciferase (relative light unit, RLU) (Left). Mutants that produced HCVpp with detectable signals were titrated against MAb IGH526 in a neutralization assay (Right). (c) Binding and (d) Neutralization of the H316A/W320A single and double mutants. The data are presented in the same manner as in (a) and (b), respectively. 
FIG. 4. Conformational flexibility of E1 peptide 315-324. The IGH526 helical peptide from the crystal structure was submitted to molecular dynamics (MD) simulations for $25 \mathrm{~ns}$ both with and without the antibody. (a) The C $\alpha$ root mean square deviation (RMSD) of the antibody-bound (blue) and unbound (green) peptides relative to the conformation in the crystal structure is plotted over the $25 \mathrm{~ns}$ simulation. (b) The Ca root mean square fluctuation (RMSF) for each residue of the antibody-bound (blue) and unbound (green) peptides is plotted over the $25 \mathrm{~ns}$ simulation. RMSF is calculated relative to the crystal structure. The models at various time points were aligned on Ala319-Met324, the region on the peptide that remains helical throughout the simulation. (c) The bound peptide conformation from the crystal structure (red) is compared to the free peptide after $25 \mathrm{~ns}$ of molecular dynamics either in the bound state (top) or the unliganded state (bottom). Ala319 and Trp320 at the N-terminus of the stable portion of the helix are highlighted. 


\section{Figure1}

(a)

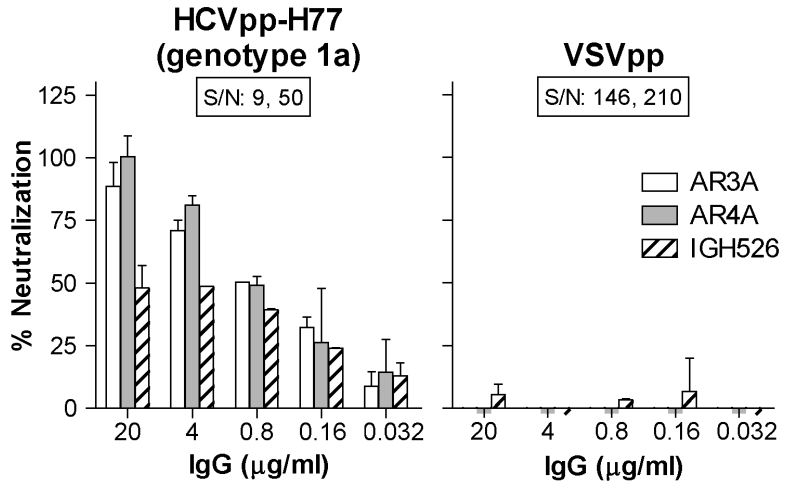

(b) Peptide inhibition of mAb IGH526 binding to E1E2

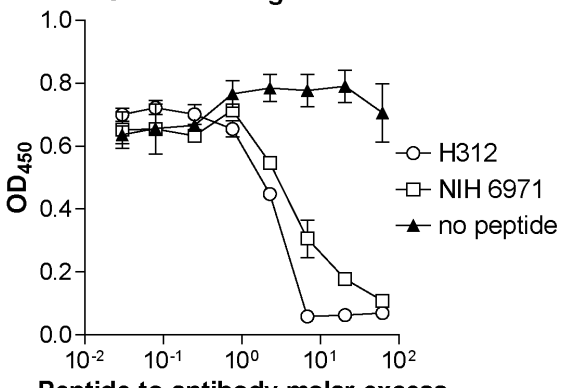

(c)

Antibody binding to native or reduced E1E2

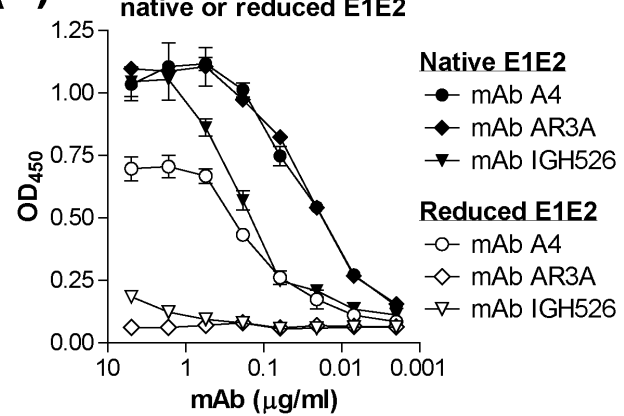

(d)

Peptide to antibody molar excess

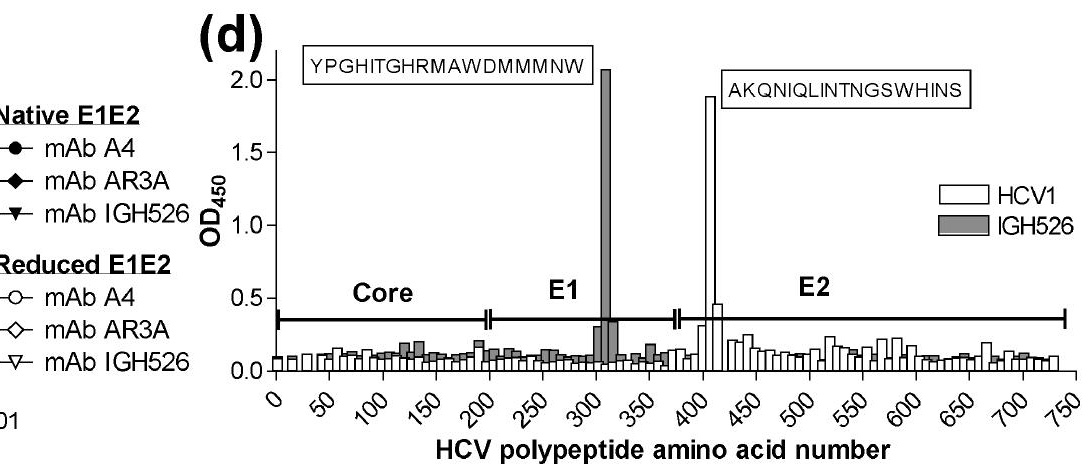




\section{Kong et al., FIG. 3}
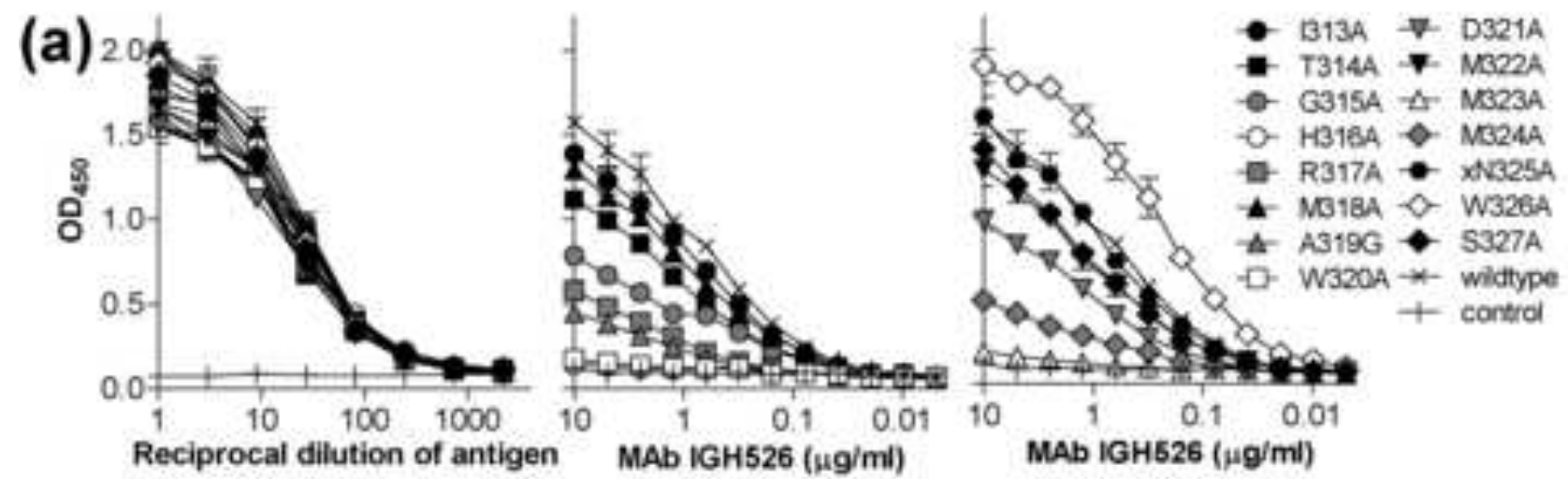

(b)
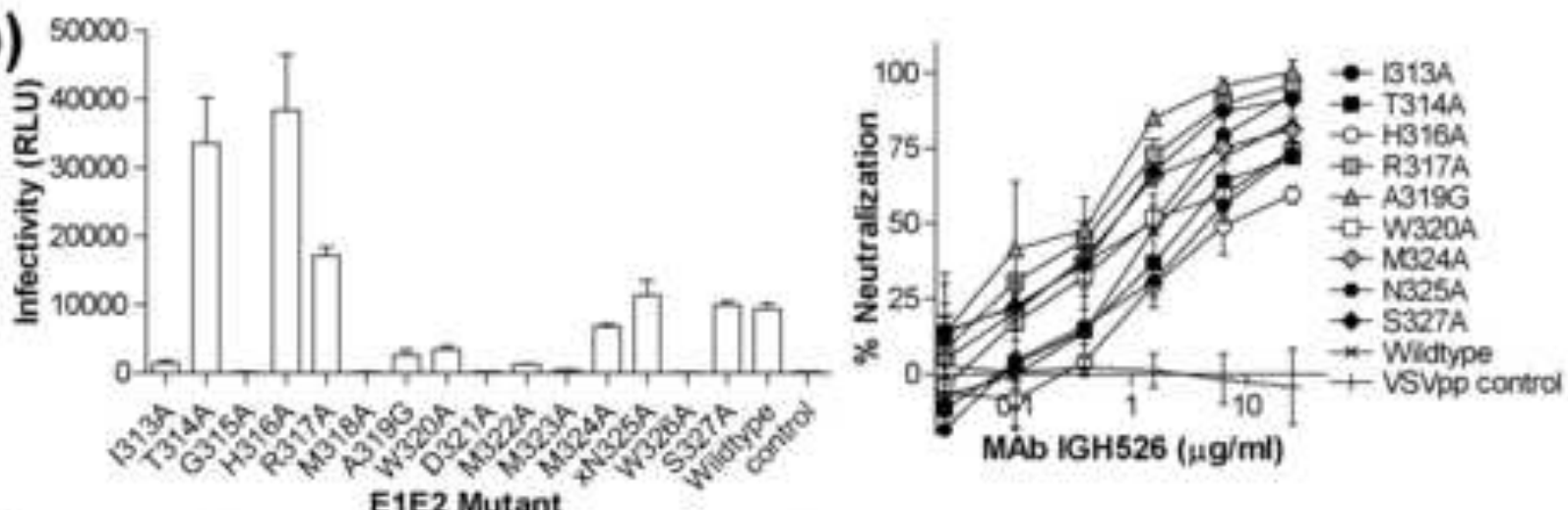

E1E2 Mutant

(c)
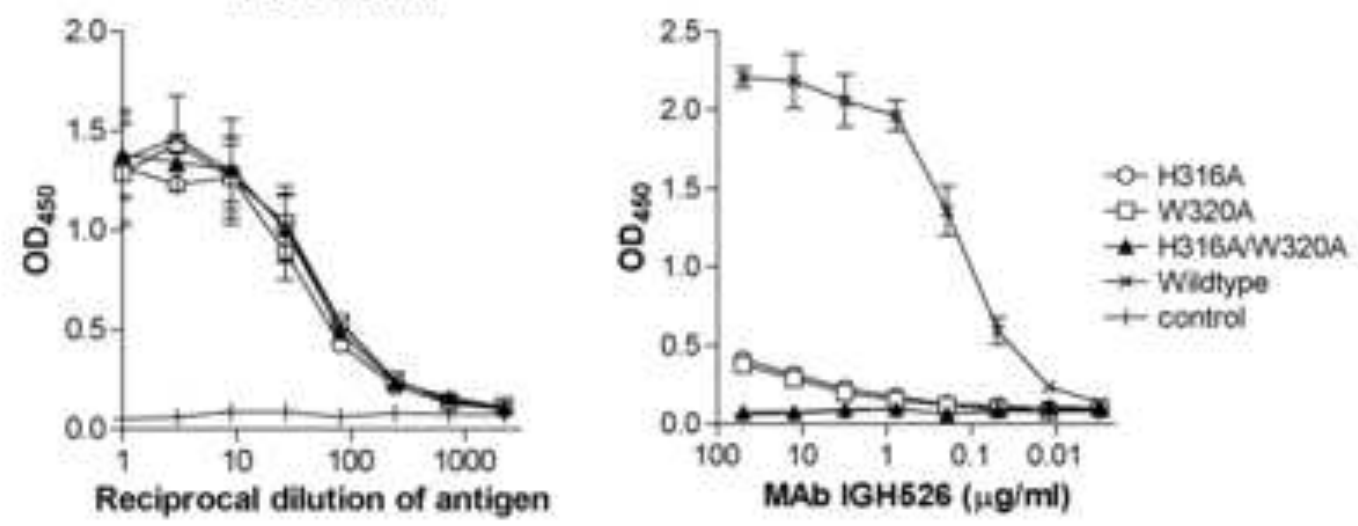

(d)
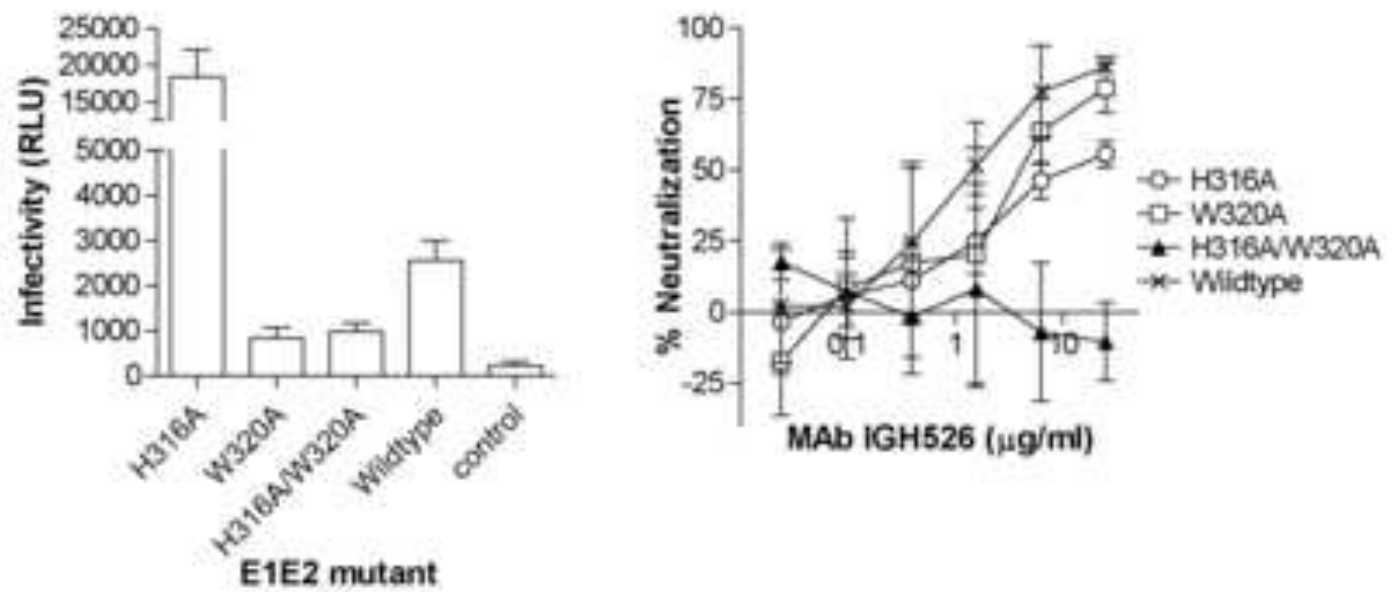
